\title{
Comparative Study Entered New Approach FMV and Control SFR for Active Compensation of Harmonic Currents in Shunt Active Power Filter
}

\author{
Loutfi Benyettou \\ Laboratory of Electrical Engineering, University of M'sila, Algeria
}

\begin{tabular}{|c|c|}
\hline Article Info & ABSTRACT \\
\hline Article history: & In this article, we discuss the problem of degradation of current in electrical \\
\hline Received Feb 16, 2018 & installations, which follows directly from the proliferation of non-linear \\
\hline Revised May 17, 2018 & which injects current harmonics at the connection point with two \\
\hline Accepted May 31, 2018 & $\begin{array}{l}\text { compensation methods the method of instantaneous active and reactive } \\
\text { power (pq method and pq method with MVF) method binds to the repository }\end{array}$ \\
\hline Keyword: & $\begin{array}{l}\text { synchronization. We will highlight two control strategies by hysteresis and } \\
\text { PWM. Simulation results using Blok set Power System (PBS)/Simulink }\end{array}$ \\
\hline Control hysteresis & Matlab show reduced THD in accordance with standard IEEE-519. \\
\hline
\end{tabular}

Control PWM

MVF

Parallel active filter

Copyright $@ 2018$ Institute of Advanced Engineering and Science. All rights reserved.

\section{Corresponding Author:}

Loutfi Benyettou,

Laboratory of Electrical Engineering,

University of M'sila,

BP-111, Riad M'Sila, 28000, Algeria.

Email: benyettou.loutfi_lge@yahoo.fr

\section{INTRODUCTION}

In recent years, the expansion of employment in the industry of non-linear-based power electronic loads has led to increasing problems with interference or distortion harmonics of power systems. This affects all industrial sectors (using dimmers, rectifiers, inverters), tertiary (computer or office lighting, commercial) and domestic(televisions, home consumer devices).

Harmonic distortion is generated by non-linear loads connected to the network and absorbs non-sinusoidal currents. These harmonic currents will in turn generate harmonic voltages at different points of the network connection. For other electrical equipment connected at these points, the harmonic pollution has adverse effects. These effects may be cited the deformation of the grid voltage at the connection point when the energy distributor is required to provide clean power. This pollution can also lead to overheating of the cables and electrical equipment or even stopped suddenly rotating machines, even the total destruction of all equipment. Therefore, suppliers of electrical energy are therefore obliged to impose standards and protect themselves against these disturbances. Standards on harmonics have been proposed by the International Electrotechnical Commission IEC61000, recommendations and IEEE Std. 519-1992 [1, 2, 3]. To cope with the phenomenon of harmonic disturbances, several solutions have been proposed. These solutions are based on diode rectifiers single and three phase to special structures, PWM rectifiers, passive filters and active filters. Traditional methods for reducing harmonics involve the use of passive filters trapping harmonic currents based LC circuits calculated in line with harmonic filtering rows. They can also be used to compensate the reactive power. However, the passive filter some problems: a lack of adaptability to variations in the impedance of the network load and possible resonance with the impedance of the network 
and in some unfavorable cases where the resonance is excited, it can a driving voltage and a higher harmonic current in significant harmonic filter capacity and the network. Thus, this solution has a major drawback that can be intolerable in these particular [1,3] circumstances. Another solution is to implement an active filter in order to avoid the drawbacks of passive filters. Many solutions for active remediation of electrical networks filters have been proposed in the literature. Those that best meet the active parallel-series (also known as Unified Power Quality Conditioner-UPQC). In the case where the source currents are non-linear, parallel active power filter (Shunt Active Power Filter-SAPF) is considered the best solution to reduce harmonic currents in applications of low to medium power. The active filter is more advantageous where rapid response is required in the presence of dynamic loads. In addition, it represents a powerful tool for versatile packaging because it is also able to compensate reactive power and the unbalanced load. The active principle of the parallel filter is to generate harmonic currents in phase opposition to those existing on the network. The current absorbed by the pollutant loads is non- sinusoidal, while the current generated by the parallel active filter is such that the current network is sinusoidal. To comply with standards imposed stringent quality electric providers and industrial consumers and to stem the increasing problems of disturbances on power systems, active filters must adapt and meet these requirements and thus optimize their topologies and control techniques. For this purpose, several research continue to be published on the parallel active filter, considering three main areas. The first is to estimate the offset current, the second is to evaluate alternative topologies, and the third area deals with control strategies that generate the control signals for the power switches. Our work is a comparative study under the same operating conditions between two control methods proposed for the identification of reference currents disrupting a nonlinear load FAP.

\section{PARALLEL STRUCTURE OF AN ACTIVE FILTER}

The general structure of a three-phase voltage type FAP is presented by Figure 1 where we distinguish the inverter and the filter output power as well as the different blocks of the party control systems part. The power section usually consists of a voltage inverter based power switches whose states of the inverter switches are controlled by the hysteresis controller or PWM, a circuit energy storage (often capacitive) and an output filter of the first order to mitigate the components due to the switching of the inverter and has connect the crossover to the power grid. [4, 5] The control-command portion is composed of a first step whose role is to identify the harmonic filter whose quality largely depends on the identification of the harmonics reference method, and a second step that performs the regulating the DC voltage. A third and final step generates the inverter control. This study is limited to cases where the source voltage is sinusoidal, and where the current drawn by the load is tainted with harmonic components. Under these conditions, the total harmonic distortion THD is well suited to describe the degree of harmonic pollution on the grid. Tables and Figures are presented center, as shown below and cited in the manuscript.

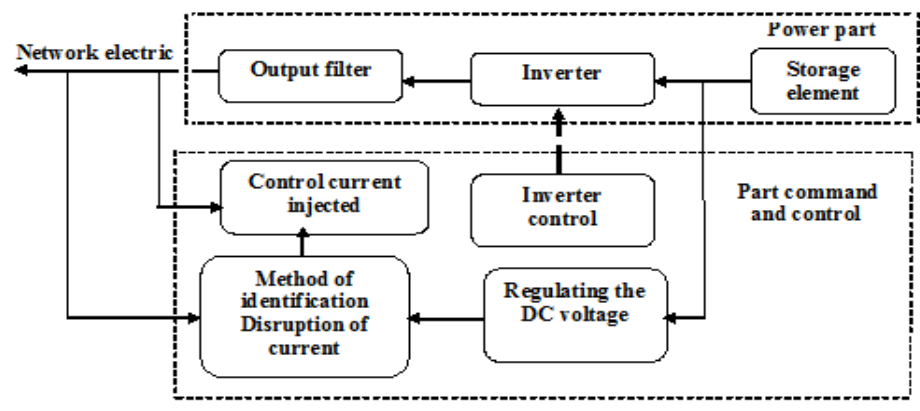

Figure 1. General Structure of a FAP voltage structure

\section{CALCULATION OF CURRENT HARMONICS}

The current consumption of the pollutant load is composed of a fundamental and harmonics. The active filter is used to generate the harmonic currents of the same magnitude but in phase opposition with those existing in the feed. To do this, we must identify the harmonic currents of the load. Several methods exist for identifying $[1,2,3]$ : The first is based on the spectral analysis of pollutant stream. The second uses a band pass filter for filtering the fundamental. The third uses the concepts of instantaneous real power and imagination. The latter is most commonly used in most crossovers because it achieves the best agreement between the static and dynamic performance. 


\subsection{Method of instantaneous active and reactive power}

The method of instantaneous active and reactive power (commonly denoted pq method) operates the Concordia transformation of voltages and line currents $[6,7]$ to calculate the instantaneous active and reactive powers. The fundamental component is converted into a DC component and the harmonic components in the AC components. By removing the DC component of the instantaneous active power (corresponding to the fundamental component of the current of the load) using a simple low-pass filter (FPB), the harmonic components can be identified. The principle of this conventional method is now briefly described. Are respectively the voltages from the point of connect $(\mathrm{Pcc})$, freedom from zero (connected to a pollutant load) and the three load currents, denoted $v_{s 1}, v_{s 2}, v_{s 3}$ and $i_{c 1}, i_{c 2}, i_{c 3}$. The transformation can reduce this Concordia a balanced two-phase system in which the axes are quadratic phase system (1-2):

$$
\begin{aligned}
& {\left[\begin{array}{l}
v_{s \alpha} \\
v_{s \beta}
\end{array}\right]=\sqrt{\frac{2}{3}}\left[\begin{array}{ccc}
1 & -\frac{1}{2} & -\frac{1}{2} \\
0 & \frac{\sqrt{3}}{2} & -\frac{\sqrt{3}}{2}
\end{array}\right] \cdot\left[\begin{array}{l}
v_{s 1} \\
v_{s 2} \\
v_{s 3}
\end{array}\right]} \\
& {\left[\begin{array}{l}
i_{c \alpha} \\
i_{c \beta}
\end{array}\right]=\sqrt{\frac{2}{3}}\left[\begin{array}{ccc}
1 & -\frac{1}{2} & -\frac{1}{2} \\
0 & \frac{\sqrt{3}}{2} & -\frac{\sqrt{3}}{2}
\end{array}\right] \cdot\left[\begin{array}{l}
i_{c 1} \\
i_{c 2} \\
i_{c 3}
\end{array}\right]}
\end{aligned}
$$

Neglecting the voltage harmonics, the actual power $p_{c}$ and imaginary power $q_{c}$ are expressed by (3):

$$
\left[\begin{array}{l}
p_{c} \\
q_{c}
\end{array}\right]=\left[\begin{array}{cc}
v_{s \alpha} & v_{s \beta} \\
-v_{s \beta} & v_{s \alpha}
\end{array}\right] \cdot\left[\begin{array}{l}
i_{c \alpha} \\
i_{c \beta}
\end{array}\right]
$$

Components of real power and instantaneous imaginary expressed as the sum of a DC component and an AC component (4):

$$
\left[\begin{array}{l}
p_{c} \\
q_{c}
\end{array}\right]=\left[\begin{array}{l}
\bar{p}_{c}+\tilde{p}_{c} \\
\bar{q}_{c}+\widetilde{q}_{c}
\end{array}\right]
$$

with:

- $\bar{p}_{c}$ : The continuous power associated to the fundamental active component of the current and voltage;

$-\bar{q}_{c}$ : The continuous power associated to the fundamental component of the reactive current and voltage;

- $\tilde{p}_{c}$ et $\widetilde{q}_{c}$ : Alternative power corresponding to the sum of the interference components of the current and voltage.

To isolate the conventional active and reactive power, it is necessary to know accurately the frequency pulsations instantaneous power formed from equation (4). It should be noted that now considers that the studied system is composed of three son that prevents zero sequence components are circulating. After identifying the pulse instantaneous power, the power filter charged isolate conventional active and reactive power can be sized. A circuit comprising a low pass filter with a subtract or can be used, as presented in Figure 2.

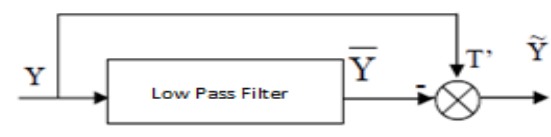

Figure 2. Diagram showing the principle of separation of powers

The order of this low-pass filter defines the dynamics and effectiveness of the identification method. In this paper, a low-pass second order filter is selected for the extraction of harmonics. The cut off frequency $\mathrm{fc}=25 \mathrm{~Hz}$ is chosen so that the filter can block any disturbing component of instantaneous power. From equation (3), we can find current component (5): 


$$
\left[\begin{array}{c}
i_{c \alpha} \\
i_{c \beta}
\end{array}\right]=\left[\begin{array}{cc}
v_{s \alpha} & v_{s \beta} \\
-v_{s \beta} & v_{s \alpha}
\end{array}\right]^{-1} \cdot\left[\begin{array}{l}
p_{c} \\
q_{c}
\end{array}\right]=\frac{1}{v_{s \alpha}^{2}+v_{s \beta}^{2}}\left[\begin{array}{cc}
v_{s \alpha} & -v_{s \beta} \\
v_{s \beta} & v_{s \alpha}
\end{array}\right] \cdot\left[\begin{array}{l}
p_{c} \\
q_{c}
\end{array}\right]
$$

By introducing (4) in (5), the currents in the axes $(\alpha, \beta)$ becomes(6):

$$
\left[\begin{array}{l}
i_{c \alpha} \\
i_{c \beta}
\end{array}\right]=\frac{1}{v_{s \alpha}^{2}+v_{s \beta}^{2}}\left[\begin{array}{cc}
v_{s \alpha} & -v_{s \beta} \\
v_{s \beta} & v_{s \alpha}
\end{array}\right] \cdot\left[\begin{array}{l}
\bar{p}_{c} \\
\bar{q}_{c}
\end{array}\right]+\frac{1}{v_{s \alpha}^{2}+v_{s \beta}^{2}}\left[\begin{array}{cc}
v_{s \alpha} & -v_{s \beta} \\
v_{s \beta} & v_{s \alpha}
\end{array}\right] \cdot\left[\begin{array}{l}
\tilde{p}_{c} \\
\tilde{q}_{c}
\end{array}\right]
$$

Depending on the function that we want to give to the FAP, we can simultaneously compensate the current harmonics and reactive power or only one. Table 1 summarizes the possible modes of compensation [8], [9]. If we want for example to compensate current harmonics and reactive power simultaneously, then we eliminate the DC component of ${ }^{p_{c}}$ using a simple LPF. In this case and after adding to the $\mathrm{AC}$ component of the instantaneous active power, active power $p_{d c}$ for regulation of the DC voltage $^{v_{d c}}$.

Table 1. Methods of Controlling the Compensation Instantaneous Power

\begin{tabular}{ccc}
\hline Type of compensation & \multicolumn{2}{c}{ Control parameter } \\
\hline Compensation of current harmonics & $p_{f}^{r e f}=p_{c}+p_{d c}$ & $\boldsymbol{q}_{f}^{\text {ref }}=\widetilde{\boldsymbol{q}}_{c}$ \\
Compensation of reactive energy & $\boldsymbol{p}_{f}^{\text {ref }}=\mathbf{O}+p_{d c}$ & $\boldsymbol{q}_{f}^{\text {ref }}=\overline{\boldsymbol{q}}_{c}$ \\
Compensation of current harmonics and reactive power & $\boldsymbol{p}_{f}^{r e f}=\widetilde{\boldsymbol{p}}_{c}+\boldsymbol{p}_{d c}$ & $\boldsymbol{q}_{f}^{r e f}=\boldsymbol{q}_{c}$ \\
\hline
\end{tabular}

The reference currents, denoted ${ }^{i_{f \alpha}^{r e f}}$ et ${ }^{i_{f \beta}^{r e f}}$, are expressed along the axes $(\alpha, \beta)$ by:

Finally, it is easy to obtain the reference currents according to the axes abc by the transformation (7):

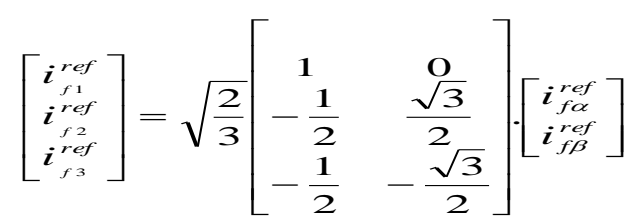

\subsection{Principle of multi-variable filter MVF}

Mr. Benhabib suggested in his thesis [1] a new filter called MVF extraction, for extracting the fundamental component of electrical signals (voltage or current) directly along the axes $(\alpha-\beta)$. The transfer function of this filter is (8):

$$
H(s)=\frac{\hat{v}_{\alpha \beta}(s)}{v_{\alpha \beta}(s)}=K \frac{(s+K)+j \omega_{c}}{(s+K)^{2}+\omega_{c}^{2}}
$$

$\left(\omega_{\mathrm{c}}\right)$ represents the fundamental pulsation $(\mathrm{fc}=50 \mathrm{~Hz}),(\mathrm{K})$ a positive constant, (v)electrical input voltage MVF and ( $\hat{v})$ is the voltage corresponding to (v) output MVF. The fundamental component of the electrical signal (voltage or current) can be extracted directly by the axes $(\alpha-\beta)$, without phase change or amplitude. From equation (8), we obtain the following two expressions as shown in (9-10). MVF used at the two-phase voltages, can effectively filter the harmonic components of the power supply voltages. Thus, its implementation can improve the performance of the filter. Figures are presented center, as shown in Figure 3 and cited in the manuscript.

$$
\begin{aligned}
& \hat{v}_{\alpha}(s)=\frac{(\mathrm{s}+\mathrm{K}) \mathrm{K}}{(\mathrm{s}+\mathrm{K})^{2}+\omega_{\mathrm{c}}^{2}} v_{\alpha}(s)-\frac{\mathrm{k} \omega_{\mathrm{c}}}{(\mathrm{s}+\mathrm{K})^{2}+\omega_{\mathrm{c}}^{2}} v_{\beta}(s) \\
& \hat{v}_{\beta}(s)=\frac{(\mathrm{s}+\mathrm{K}) \mathrm{K}}{(\mathrm{s}+\mathrm{K})^{2}+\omega_{\mathrm{c}}^{2}} v_{\beta}(s)+\frac{\mathrm{k} \omega_{\mathrm{c}}}{(\mathrm{s}+\mathrm{K})^{2}+\omega_{\mathrm{c}}^{2}} v_{\alpha}(s)
\end{aligned}
$$




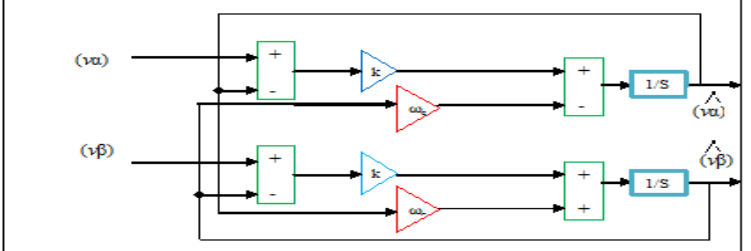

Figure 3. Block diagram MVF

\subsection{Method called the reference related to synchronization}

This method, introduced by [8], [9], the processing also operates Concordia but applied only to the line currents of the load $i_{c 1}, i_{c 2}$ and $i_{c 3}$. Then, a second processing is performed to switch the line currents in dq, which transforms the fundamental component of current in a DC component and harmonic current components in the AC components. This allows us to eliminate using a simple low pass filter, the DC component of the current. The major advantage of this method compared to previous lies in the fact that any tensions harmonics have no more influence on the identified current and therefore the filter will be better. Its principle is set out below. Are the line currents of a three-phase system without zero sequence. The transformation can reduce this Concordia phase system to a two-phase equilibrium system, as above by the following relationship (11):

$$
\left[\begin{array}{l}
i_{c \alpha} \\
i_{c \beta}
\end{array}\right]=\sqrt{\frac{2}{3}}\left[\begin{array}{ccc}
1 & -\frac{1}{2} & -\frac{1}{2} \\
0 & \frac{\sqrt{3}}{2} & -\frac{\sqrt{3}}{2}
\end{array}\right] \cdot\left[\begin{array}{l}
i_{c 1} \\
i_{c 2} \\
i_{c 3}
\end{array}\right]
$$

By generating signals with a P. L. L $\cos (\hat{\theta})$ and $\sin (\hat{\theta})$ derived from the fundamental tension network, we obtain the expression of the currents in the dq system (12) [9]:

$$
\left[\begin{array}{l}
i_{c d} \\
i_{c q}
\end{array}\right]=\left[\begin{array}{cc}
\sin (\hat{\theta}) & -\cos (\hat{\theta}) \\
\cos (\hat{\theta}) & \sin (\hat{\theta})
\end{array}\right]^{-1} \cdot\left[\begin{array}{l}
i_{c \alpha} \\
i_{c \beta}
\end{array}\right]
$$

These components may then be expressed as the sum of a DC component and an AC component (13):

$$
\left[\begin{array}{l}
i_{c d} \\
i_{c q}
\end{array}\right]=\left[\begin{array}{l}
\bar{i}_{c d}+\widetilde{i}_{c d} \\
\bar{i}_{c d}+\widetilde{i}_{c d}
\end{array}\right]
$$

with:

$\bar{i}_{c d}$ and $\bar{i}_{c q}:$ The DC components of $i_{c d}$ and ${ }^{i_{c q}}$,

$\tilde{i}_{c d}$ and $\tilde{i}_{c q}$ : ac components of $i_{c d}$ and $i_{c q}$

Equation (12), we can deduce the components of current $\alpha-\beta$ (14):

$$
\left[\begin{array}{l}
i_{c \alpha} \\
i_{c \beta}
\end{array}\right]=\left[\begin{array}{cc}
\sin (\hat{\theta}) & \cos (\hat{\theta}) \\
-\cos (\hat{\theta}) & \sin (\hat{\theta})
\end{array}\right]^{-1} \cdot\left[\begin{array}{l}
i_{c d} \\
i_{c q}
\end{array}\right]=\left[\begin{array}{cc}
\sin (\hat{\theta}) & \cos (\hat{\theta}) \\
-\cos (\hat{\theta}) & \sin (\hat{\theta})
\end{array}\right] \cdot\left[\begin{array}{l}
i_{c d} \\
i_{c q}
\end{array}\right]
$$

Soint (15):

$$
\left[\begin{array}{l}
i_{c \alpha} \\
i_{c \beta}
\end{array}\right]=\left[\begin{array}{cc}
\sin (\hat{\theta}) & \cos (\hat{\theta}) \\
-\cos (\hat{\theta}) & \sin (\hat{\theta})
\end{array}\right] \cdot\left[\begin{array}{c}
\bar{i}_{c d} \\
\bar{i}_{c q}
\end{array}\right]+\left[\begin{array}{cc}
\sin (\hat{\theta}) & \cos (\hat{\theta}) \\
-\cos (\hat{\theta}) & \sin (\hat{\theta})
\end{array}\right] \cdot\left[\begin{array}{c}
\widetilde{i}_{c d} \\
\widetilde{i}_{c q}
\end{array}\right]
$$

Next we give the function active power filter [8], we can also compensate with this command is the current harmonics and reactive energy or only one of the two. Table 2 summarizes the modes of compensation possible.

Comparative Study Entered New Approach FMV And Control SFR For Active ... (Loutfi Benyettou) 
Table 2. Methods Compensation Control Repository Binds to Synchronously

\begin{tabular}{ccl}
\hline Type of compensation & \multicolumn{3}{c}{ Control parameters } \\
\hline Compensation of current harmonics & $\boldsymbol{i}_{f d}^{r e f}=\widetilde{\boldsymbol{i}}_{c d}+\boldsymbol{i}_{d c}$ & $\boldsymbol{i}_{f q}^{r e f}=\widetilde{\boldsymbol{i}}_{c q}$ \\
Compensation of reactive energy & $\boldsymbol{i}_{f d}^{r e f}=\mathbf{O}+\boldsymbol{i}_{d c}$ & $\boldsymbol{i}_{f q}^{r e f}=\overline{\boldsymbol{i}}_{c q}$ \\
Compensation of current harmonics and reactive power & $\boldsymbol{i}_{f d}^{r e f}=\widetilde{\boldsymbol{i}}_{c d}+\boldsymbol{i}_{d c}$ & $\boldsymbol{i}_{f q}^{r e f}=\boldsymbol{i}_{c q}$ \\
\hline
\end{tabular}

The reference currents are expressed by (16):

$$
\left[\begin{array}{c}
i_{f \alpha}^{r e f} \\
i_{f \beta}^{r e f}
\end{array}\right]=\left[\begin{array}{cc}
\sin (\hat{\theta}) & \cos (\hat{\theta}) \\
-\cos (\hat{\theta}) & \sin (\hat{\theta})
\end{array}\right] \cdot\left[\begin{array}{l}
i_{f d}^{r e f} \\
i_{f q}^{r e f}
\end{array}\right]
$$

After the choice of control parameters, the inverse transformation can be traced back to the Concordia reference currents (17):

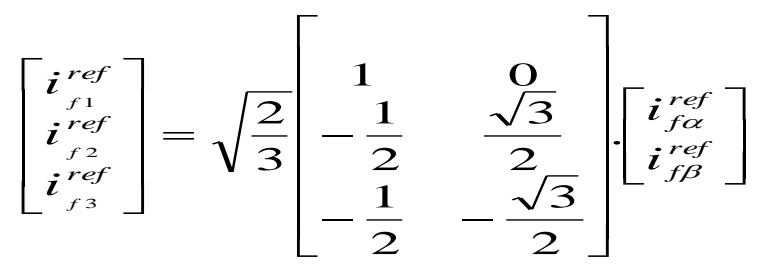

\section{CURRENT CONTROL BY HYSTERESIS}

The method is based on the comparison of the difference $\varepsilon$ between the current reference and the measured currents with a fixed band. Each violation of this band gives a switching command switches to 4. Figures are presented center, as shown in Figure 4 and cited in the manuscript.

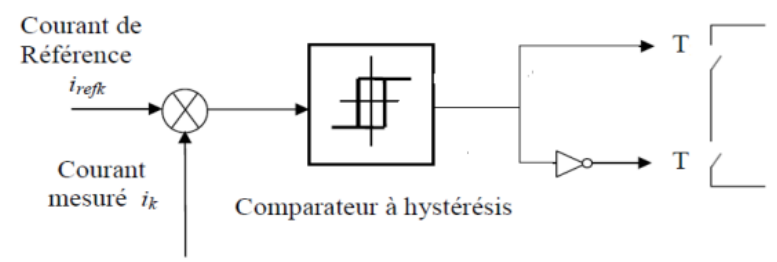

Figure 4. Principle of current control by hysteresis

\section{CURRENT CONTROL BY PWM}

The PWM control principle is described in Figure 5. In this case, the difference between the current reference if and the actual current ifref is applied to the input of a controller. The output signal of the controller, called modulator, is then compared with a triangular wave of fixed frequency (carrier) to determine the order of switching of the switches. The frequency of the triangular carrier therefore sets the switching frequency of the power semiconductors.

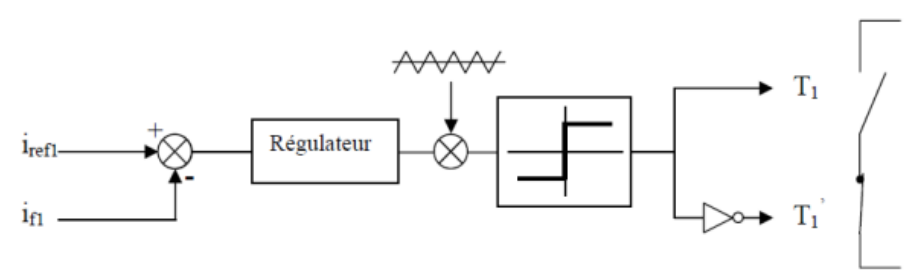

Figure 5. Principle of command current by PWM 


\section{SIMULATION OF RESULTS}

The simulation of the direct control in the phase marker based on the method binds to the repository synchronization or the theory of instantaneous power (pq) was conducted with the following parameters:

- The load current is increased $50 \%$ to $\mathrm{t}=0,3 \mathrm{~s}$

- The value of the DC voltage is equal to $600 \mathrm{~V}$

- The hysteresis band attached to 3A, for control by hysteresis

- The switching frequency is set at $13.5 \mathrm{KHz}$. for PWM control.

- Drop filter low pass second order cutoff frequency equal to $25 \mathrm{~Hz}$.

- The parameter K of MVF was chosen equal to 80.

Table 3 includes all network settings and pollutant loads used in the simulation.

Table 3. Simulation Settings

\begin{tabular}{cc}
\hline Parameters & numerical values \\
\hline Voltage effective $\mathrm{E}_{\mathrm{s}}[\mathrm{v}]$ & 240 \\
Frequency $f$ & 50 \\
Line resistance $\mathrm{R}_{s}[\mathrm{~m} \Omega]$ & 1.59 \\
Line choke $\mathrm{L}_{s}[\mu \mathrm{H}]$ & 45.56 \\
apparent power $\mathrm{S} \mathrm{KVA}$ & 400 \\
Load resistance $\mathrm{DC} \mathrm{R}_{\mathrm{c}}[\mathrm{m} \Omega]$ & 2.73 \\
Load inductance $\mathrm{DC} \mathrm{L}_{c}[\mu \mathrm{H}]$ & 23.19 \\
Filter resistance $\mathrm{R}_{\mathrm{f}}[\mathrm{m} \Omega]$ & 6.87 \\
Filter inductance $\mathrm{L}_{\mathrm{f}}[\mu \mathrm{H}]$ & 100 \\
Voltage $\mathrm{Vdc}[\mathrm{v}]$ & 600 \\
\hline
\end{tabular}

\subsection{Results of simulation of the overall network load before the nonlinear filter}

The previous figure shows the load current (ic1) the first phase and the harmonic spectrum. The current THD for this load is $23,72 \%$. The THD is calculated for the first forty harmonics according to "IEC" Figures are presented center, as shown in Figure 6, 7 and cited in the manuscript.

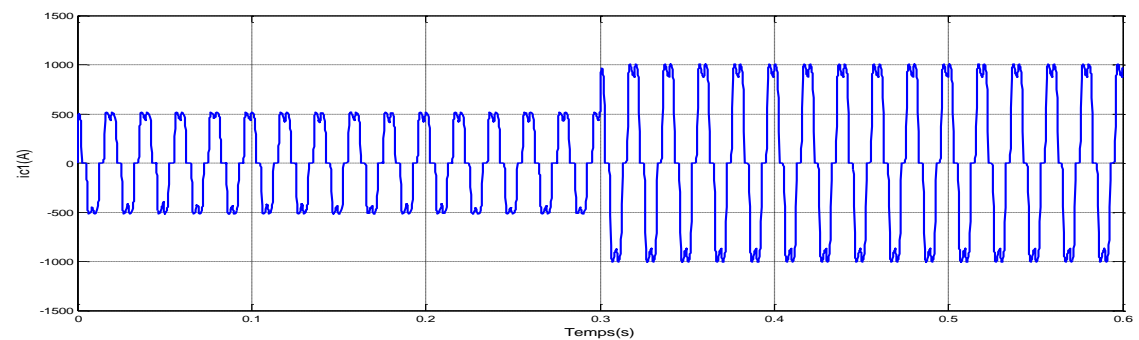

Figure 6. Load current (phase 1)

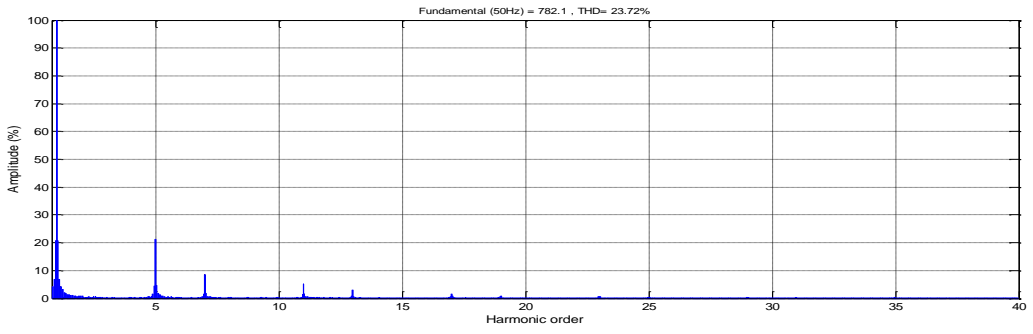

Figure 7. Harmonic spectrum of the load current (Phase 1) THD=23.72\%

\subsection{Direct control method based on the instantaneous power (PQ)}

\subsubsection{Results of simulation using the hysteresis control}

Figures 8 The source current harmonic spectrum after compensation (phase 1) THD=6.81\% are presented center, as shown below and cited in the manuscript. 


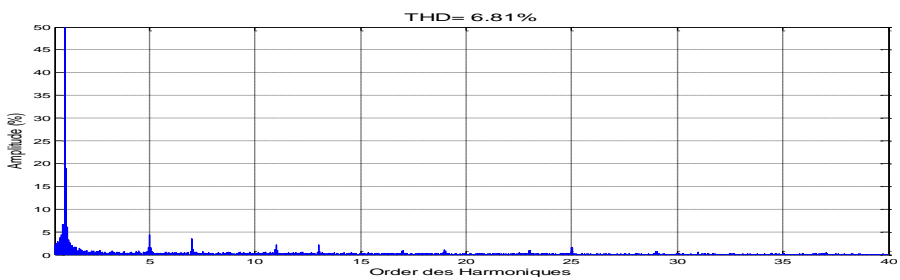

Figure 8 . The source current harmonic spectrum after compensation (phase 1 ) $\mathrm{THD}=6.81 \%$

\subsubsection{Simulation results using the command hysteresis with MVF}

Figure 9 is currents of non-linear load ic1, is 1 of source and that of if 1 crossover and Figure 10. The source current harmonic spectrum after compensation (phase 1) $\mathrm{THD}=1.68 \%$ are presented center, as shown below and cited in the manuscript.

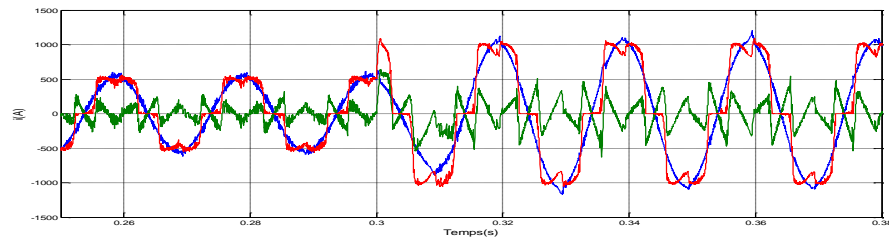

Figure 9. Currents of non-linear load ic1, is1 of source and that of if 1 crossover

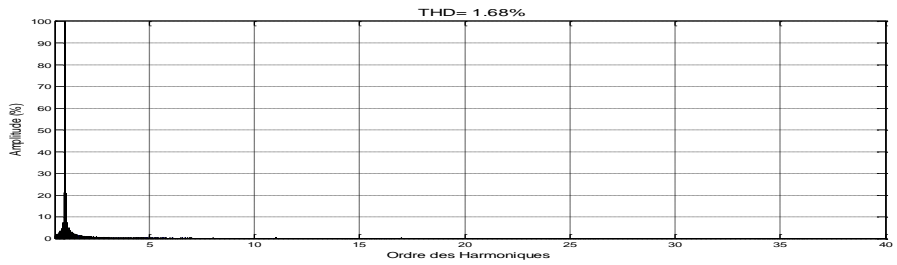

Figure 10. The source current harmonic spectrum after compensation (phase 1) THD=1.68\%

\subsubsection{Simulation results using the PWM command}

In Figures 11 Currents of non-linear load ic1, is 1 of source and that of if 1 crossover and Figure 12. The source current harmonic spectrum after compensation (phase 1 ) $\mathrm{THD}=1.73 \%$ are presented center, as shown below and cited in the manuscript.

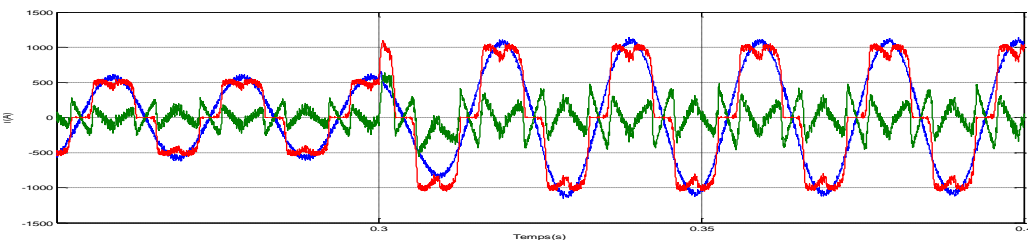

Figure 11. Currents of non-linear load ic1, is 1 of source and that of if 1 crossover

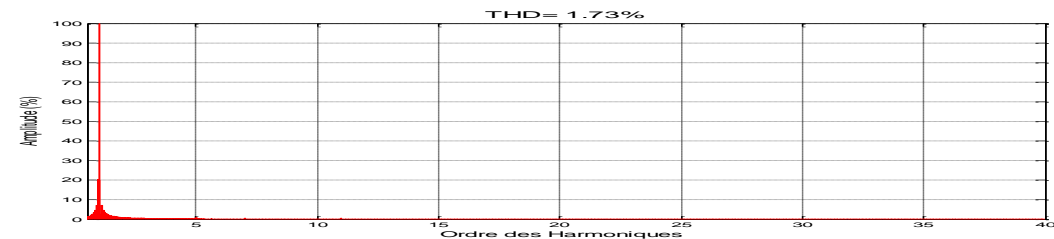

Figure 12. The source current harmonic spectrum after compensation (phase 1) THD=1.73\% 


\subsection{Direct control method based on the synchronous reference frame SFR}

\subsubsection{Results of simulation using the hysteresis control}

Figure 13 currents of non-linear load ic1, is 1 of source and that of if 1 crossover and Figure 14. The source current harmonic spectrum after compensation (phase 1) THD $=1.23 \%$ are presented center, as shown below and cited in the manuscript.

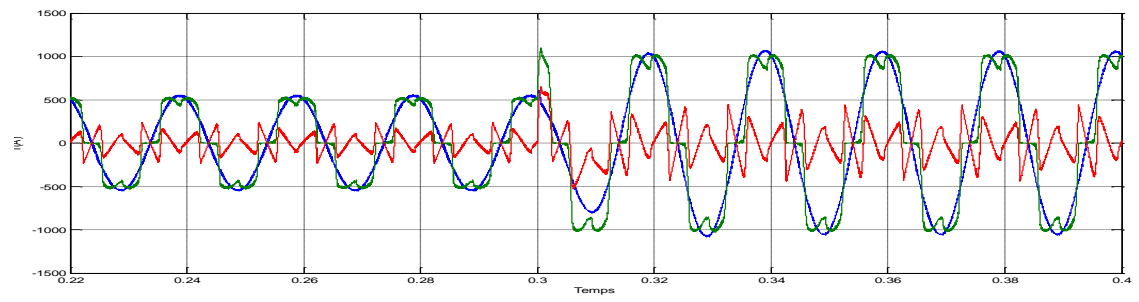

Figure 13. Currents of non-linear load ic1, is1 of source and that of if 1 crossover

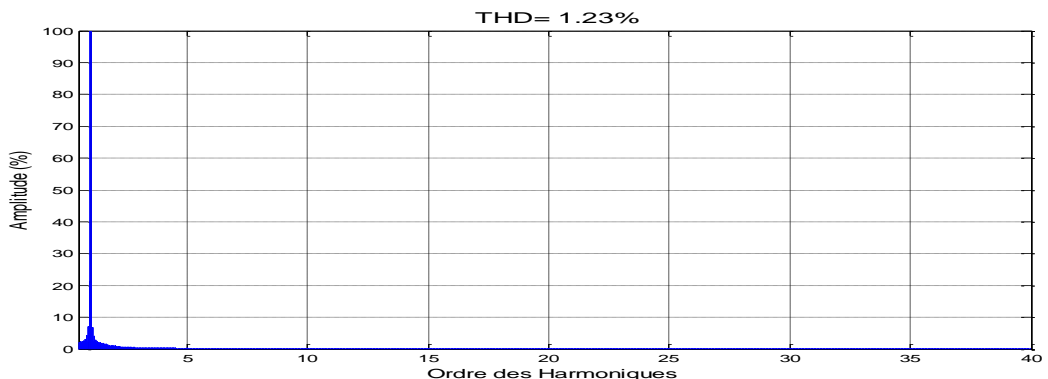

Figure 14. The source current harmonic spectrum after compensation (phase 1) $\mathrm{THD}=1.23 \%$

\subsubsection{Simulation results using the PWM command}

Figure 15. Currents of non-linear load ic1, is 1 of source and that of if 1 crossover and Figure 16. The source current harmonic spectrum after compensation (phase 1) $\mathrm{THD}=1.36 \%$ are presented center, as shown below and cited in the manuscript.

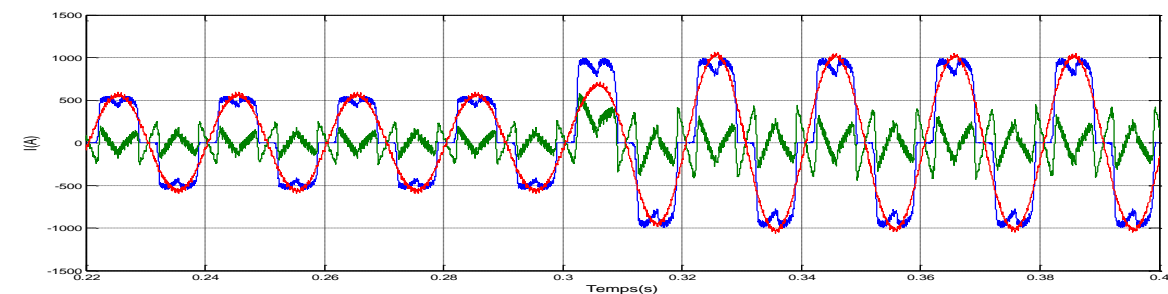

Figure 15. Currents of non-linear load ic1, is 1 of source and That of if 1 crossover

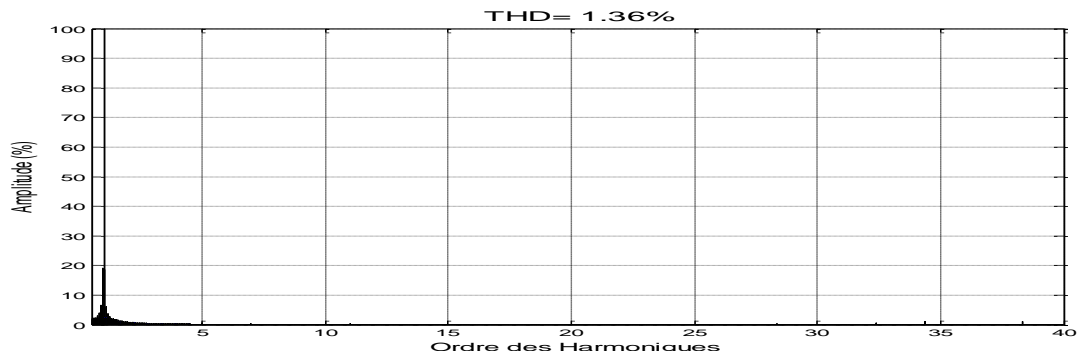

Figure 16. The source current harmonic spectrum after compensation (phase 1) THD=1.36\%

Comparative Study Entered New Approach FMV And Control SFR For Active ... (Loutfi Benyettou) 


\section{CONCLUSION}

The table below present the summary results of the different simulations obtained for the direct control strategy applied to the topologies of active power filter has two-level inverter. From the results obtained by the simulation made under the same operating conditions of the FAP next two proposed methods, the component method reference related to the timing and method of instantaneous active and reactive power with MVF detected disruptive current successful they effectively reduced the THDi after compensation, we found that the FAP hysteresis control method gave satisfactory results and slightly better than the PWM method as shows in Table 4.

The results obtained with the two commands show that the implementation of the active filter can significantly reduce the harmonic content of the current source, which results in decreased after filtering THD well below 5\%. We see that THDS obtained with the so-called hysteresis orders are lower than that obtained with the PWM. As against, hysteresis, despite its simplicity, has the disadvantage of a variable switching frequency, where the presence of a large number of harmonics in the current wave. PWM technique, easy to use, then provides a fixed frequency operation, harmonic content, but also has fully identified by its structure, limited dynamic properties.

Table 4 Synthesis of the Results

\begin{tabular}{ccc}
\hline & Controlled hysteresis & Controlled MLI \\
\hline controlled Direct p-q & 6.81 & - \\
controlled direct p-q with MVF & 1.68 & 1.73 \\
controlled direct SRF & 1.23 & 1.36 \\
\hline
\end{tabular}

\section{REFERENCES}

[1] M. Abdusalam, "Structures and Strategies for Control of Parallel and Hybrid Active Filters with Experimental Validations," PhD Thesis, Henri Poincaré University, Nancy-I, May 2008.

[2] N. Bruyant, "Generalized Study and Control of Parallel Active Filters, Global or Selective Compensation of Harmonics, Balanced or Unbalanced Regime," Ph.D Thesis, University of Nantes, France, 1999.

[3] A. Sahbani, M. Braiek, M. Dami and M. Jemli, "Control of a Three-Phase Shunt Filter by Fuzzy Logic," 3rd International Conferences SETIT, Tunisia, 27-31, March 2005.

[4] A. Rahmouni, "Performance Comparison of Two New Control Methods of a Parallel Active Filter", ACTA, vol53, 2012, pp278-282.

[5] Y. Kusuma Latha, Ch. Saibabu, Y. P. Obulesh, Control Strategy for Three Phase Shunt Active Power Filter with Minimum Current Measurements, (IJECE),Vol1, No1,2011, pp. 31-42.

[6] K. Shahram, "Continuity of Service of Three-Phase Power Converters and FPGA Prototyping in the Loop: Application to Parallel Active Filter," PhD thesis, Henri Poincaré University, Nancy-I, January 2009.

[7] R. Balasubramanian, S. Palani, Simulation and Performance Evaluation of Shunt Hybrid Power Filter for Power Quality Improvement Using PQ Theory, (IJECE),Vol6, No6,2016, pp. 2603-2609.

[8] B. Choukri, "Contribution to the Study of the Different Topologies and Commands of Parallel Active Filters With Structure Tension: Modeling, Simulation and Experimental Validation of the Order," Doctoral Thesis, Henri Poincaré University, Nancy-I, December 2004.

[9] A. MORSLI, "Depollution of Low-Voltage Electrical Networks Using a Two-Level Parallel Active Filter Controlled by The PQ," ACTA algorithm, vol 53,2012, pp105-111.

\section{BIOGRAPHY OF AUTHOR}

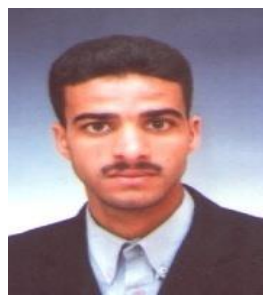

Benyettou Loutfi was born in M'sila, Algeriain 1979. He received his Engineer degree in Electronics and Magister degree in industrial control from M'sila University in 2002 and 2006 respectively. $\mathrm{He}$ received his Ph. D. in electrical engineering from Bechar University, Algeria, in 2016. He was recruited in 2009 as electronics assistant professor in University of M'sila. His scientific interests are power quality conditioning, DSP and digital control, control and diagnostic. He is member of several research projects at University of Msila and Electrical Engineering Laboratory of Msila University 